\title{
Em face do anômalo: masculinidade, lesbianidade e performance Drag King em Amor na Ponta da Língua
}

Facing the anomalous: masculinity, Lesbianity and Drag Kings in Tipping The Velvet

Frente a lo anómalo: masculinidad, lesbianidad y actuación de Drag King en Tipping the Velvet

\section{Resumo}

Este artigo discute masculinidade em mulheres e lesbianidade em um produto audiovisual, por meio de um exercício analítico operado sobre a personagem Nan, da minissérie televisiva Amor na Ponta da Língua (2002). Para tanto, resgata o conceito de anômalo (DELEUZE \& GUATTARI, 1997) e a teoria performativa (BUTLER, 2013), de modo a possibilitar uma discussão sobre a resistência à abjeção e emergência do anômalo. A etnografia de tela (RIAL, 2004) compõe a metodologia. A partir do exercício analítico operado, Nan foi concebida como em face do anômalo, convocada a forjar uma aliança com uma personagem Drag King. Consequentemente, Nan ressignificou os limites de inteligibilidade do gênero e da sexualidade por meio do audiovisual, produzindo aquilo que nomeei, com base na teoria deleuze-guattariana, devir-sapatão.

Palavras-chave: masculinidade feminina; lesbianidade; séries; anômalo

\begin{abstract}
This paper discusses masculinity in women and lesbianity on a Tv show through an analysis on the character Nan, from the Tv show Tipping The Velvet (2002). To this end, it rescues the concept of anomalous (DELEUZE \& GUATTARI, 1997) and the performative theory (BUTLER, 2013), in order to enable a discussion about the resistance to abjection as a process and the emergence of the anomalous. The theoretical and methodological perspective also includes the screen ethnography

\footnotetext{
${ }^{1}$ Doutore em educação (UFRGS), graduade em comunicação social (UFRGS) e letras - inglês (Estácio de Sá). Professore da rede estadual de educação básica do Rio Grande do Sul. E-mail: daniconegatti@gmail.com - ORCiD: 0000-0002-1143-2277.
} 
(RIAL, 2004). From the analytical exercise performed, Nan was conceived as facing the anomalous, being summoned to forge an alliance with a Drag King character. Consequently, Nan redefined the limits of gender and sexuality intelligibility, producing what I have named, based on the Deleuzean theory, becoming-dyke.

Keywords: female masculinity; lesbianity; tv series; anomalous

\section{Resumen}

Este artículo analiza la masculinidad en la mujer y la lesbianidad a través de un ejercicio analítico sobre el personaje Nan, de la miniserie de televisión Amor na Ponta da Língua (2002). Por tanto, rescata el concepto de anómalo (DELEUZE \& GUATTARI, 1997) y la teoría performativa (BUTLER, 2013), para permitir una discusión sobre la resistencia a la abyección y la emergencia de lo anómalo. La perspectiva teórica y metodológica de este texto también comprende la etnografía en pantalla (RIAL, 2004). A partir del ejercicio analítico realizado, Nan fue concebida como frente a lo anómalo, convocada para forjar una alianza con un personaje Drag King. En consecuencia, Nan redefinió los límites de la inteligibilidad del género y la sexualidad, produciendo lo que llamé, basado en la teoría deleuzeana, devenir-dique.

Palabras clave: masculinidad femenina; lesbianidad; serie; anómalo

\section{Introdução}

O presente artigo é parte de uma pesquisa sobre as formas de constituição, em séries televisivas e de $\mathrm{VoD}$, do que convencionei nomear devir-sapatão² (CONEGATTI, 2020). Neste artigo, especificamente, o devir-sapatão emerge a partir da lesbianidade e de uma ambiguidade de gênero (HALBERSTAM, 1998), que aqui desponta para a masculinidade, a partir da trajetória narrativa de uma personagem.

Nan Astley, personagem em questão, advém da série Tipping The Velvet (SAX, 2002), veiculada no Brasil com o nome Amor na Ponta da Língua 3 , pelo canal GNT. Nan é uma jovem que vive no interior da Inglaterra e mostra-se bastante

\footnotetext{
2 Conceito elaborado a partir da noção de devir de Deleuze e Guattari. Sua composição se dá, primariamente, por meio de três eixos teóricos também derivados da teoria dos autores citados: des/reterritorialização, multiplicidade e plano de imanência. É proposto na pesquisa como ferramenta teórico-analítica para discutir possíveis tensões de gênero e sexualidade em relação com suas matrizes, e os efeitos de tais tensões.

${ }^{3}$ Ainda que o título deste artigo faça referência ao nome em português, opto por utilizar a nomenclatura inglesa, sobretudo porque os trabalhos referenciados aqui sobre a série são internacionais e fazem uso não apenas da versão inglesa do nome, mas da sigla correspondente TTV. Assim, para não tornar o texto confuso com nomes diversos, opto por utilizar a mesma referência desses trabalhos.
} 
desconfortável com a vida heteronormativa e cisgênero que leva, sendo convocada ao encontro com o anômalo (DELEUZE \& GUATTARI, 1997) sobretudo por meio de uma performance Drag King realizada pela personagem Kitty, que, nesse caso, oferece à Nan um convite à ressignificação da masculinidade e de sua própria sexualidade.

Para dar conta de mostrar analiticamente a insurgência do anômalo, é empregada uma discussão que compõe dois eixos teóricos: a performatividade, em Judith Butler (2013), e o anômalo, com base em Deleuze e Guattari (1997), mas traduzido sobretudo por uma aproximação da masculinidade. A primeira se faz importante na medida em que possibilita que, nas análises, a diferença dê forma ao anômalo diante da repetição imperfeita de atos estilizados (BUTLER, 2013)4, isto é, de práticas formativas/produtivas de gênero (BUTLER, 2000). A segunda permite delimitar a compreensão de anômalo, ainda que com o auxílio da teoria performativa, dentro de um marco voltado sobretudo para o gênero e para a sexualidade. Na articulação entre ambas as teorias, fez-se também espaço para apontar a escassez de trabalhos sobre masculinidades em mulheres, um dos pontos que demonstra a importância do exercício teórico-analítico empregado aqui.

A seção seguinte à articulação teórica compreende a apresentação da série e das personagens, incluindo, também, os critérios de escolha e os processos metodológicos, que aqui foram articulados sobretudo a partir da etnografia de tela (RIAL, 2004). Consecutivamente, apresento a discussão teórico-analítica; por fim, as considerações finais resgatam os principais resultados.

\section{Preparar o território para o anômalo: a performatividade}

Para Judith Butler (2014), a linguagem está no centro da produção e regulação do gênero - o que não é o mesmo que afirmar que o gênero resume-se à linguagem, mas sim que é por meio dela que existimos e fazemos existir o mundo. Isto posto, gênero não pode ser compreendido como algo anterior às suas formas de regulação, mas como produto dessas, a partir de um processo linguístico - e consequentemente material 5 - de sujeição que não é outra coisa senão gênero. Nesse sentido, não há produção de diferença sexual fora dos marcos de gênero, e, por consequência, este

\footnotetext{
${ }^{4}$ Não trabalho com o conceito de "falo lésbico" butleriano justamente por não considerar este um estudo psicanalítico em si. Ademais, a teoria performativa mostrou-se suficiente no processo de análise do efeito constitutivo da linguagem.

${ }^{5}$ Para uma explicação detalhada da relação entre materialidade e linguagem, ver Butler (1993).
} 
emerge como uma das formas que o poder assume. Ou seja, seu aparato regulador, disciplinar e producente é ele próprio generificado.

Contudo, gênero, enquanto poder, engendra algo mais amplo que as práticas que institui. Mesmo que seja o resultado das suas próprias formas de regulação, ele (o gênero) pode delas se apartar (BUTLER, 2000). Dizendo de outro modo, no lugar de pensar a hegemonização da produção generificada, Butler propõe que as formas de fazer gênero não são o gênero, mas sim o meio pelo qual ele permanece produzido, imerso em uma relação binária e limitada. Suas práticas, portanto, assim como se aproximam de suas matrizes, podem delas apartar, produzindo algo outro que não aquilo que compõe, efetivamente e de forma confinada, gênero. De fato, ao conceber gênero e práticas regulatórias como instâncias distintas, ainda que correlatas, Butler possibilita duas ponderações: a primeira, o entendimento de que não é uma prática que concebe inteligibilidade de gênero a determinado corpo. Ou seja, gestos considerados delicados e "afetados" não seriam suficientes para tornar inteligível um corpo enquanto feminino, observe-se qualquer homem cisgênero que constitua feminilidade apenas por meio dessas práticas. Mais do que práticas, efeitos das mais diversas ordens precisam coexistir para produzir um gênero (em detrimento de outro) em um corpo. Como em uma balança - metaforicamente semelhante à balança de Thêmis ${ }^{6}$, aqui vendada porque alheia aos modos de fazer o gênero -, as práticas engendram pesos e medidas diferentes e inteligíveis para ambos os lados, que podem coexistir em um corpo, ainda que de modos distintos e de mais ou menos "peso". A segunda ponderação possibilita uma espécie de fôlego criativo frente a uma teorização que toma a linguagem mais como produtora do que como produto. Tal potencialidade é intensificada a partir do conceito butleriano de performatividade (BUTLER, 2013).

Para pensar na força regulatória e produtiva da norma de gênero sobre os corpos, mas também em seus limites, Butler (2013) propõe o conceito de performatividade. Seu conceito recupera a noção de "performativo" proposta pelo linguista Austin, e enfatiza o aspecto construído do gênero e do sexo, assim como seu caráter (re)citacional, este último concebido por Jacques Derrida (1991). Butler argumenta que é por meio da repetição de atos estilizados que o gênero é produzido

6 Originária da mitologia grega, é considerada a Deusa da justiça. Seu nome significa "lei divina". Carrega uma balança, para representar o equilíbrio, e uma espada, cujo símbolo diz respeito ao poder. Sua venda, acrescida posteriormente e, portanto, sem origem no mito grego que a criou, indica uma visão imparcial da realidade. Explicação baseada em: Cruz e Abreu (2016). 
num corpo e, por consequência, o indivíduo se torna sujeito. Tais atos precisam ser repetíveis para fazerem-se inteligíveis enquanto gênero (mas não podem ser reduzidos a ele, como dito). Nesse sentido, o sujeito emerge como produto da performatividade, o que não significa que não possa, com ela, manter uma relação conflituosa, uma vez que, se as práticas não são o gênero, também não podem ser reduzidas ao efeito formativo, isto é, ao efeito do gênero naturalizado. Ao praticar o gênero, consequentemente, o indivíduo pode naturalizá-lo, estabilizá-lo, mas, também, pode produzir outras possibilidades, conceber práticas distintas daquelas que sustentam o gênero.

A este respeito, é importante explicar que a compreensão de prática butleriana não se resume àquela derivada do senso comum. Mais do que simples prática, compõe um modo de existência que produz um tipo de materialidade (e inteligibilidade) em detrimento de outro. Neste marco teórico, portanto, "prática" engendra materialidade. Consequentemente, o gênero é um efeito, isto é, pode ser atualizado na justa medida em que é performativizado - isto é, tornado prática reiterativa e citacional. Consequentemente, e de acordo com Salih (2013), estudiosa da teoria performativa de Butler, a repetição e a citacionalidade estão inexoravelmente destinadas a produzir deslocamento, ou seja, destinadas a atualizar, eventualmente, o próprio gênero.

Do modo como a performatividade é concebida, possibilita identificar nas personagens Nan e Kitty, inevitavelmente sujeitas ao gênero, repetições de atos, gestos e composições da ordem de uma matriz de gênero, mas, sobretudo, localizar as fissuras, deslocamentos, oxigenações produtivas. Tais territórios, em certo sentido inominados, são efeitos de um entre: entre gêneros e entre sexualidades, entre práticas performativas e refratárias, entre discursos e materialidade, configurando-se, neste texto, a partir da figura do anômalo.

\section{Preparar o território para a masculinidade na mulher: o anômalo}

Enquanto expressão de outros corpos que não o do homem, a masculinidade ainda é pouco estudada no Brasil. A título de ilustração, cito aqui dois tradicionais 
periódicos brasileiros7 especializados em gênero e sexualidade, que, juntos, somam $1^{8}$ artigo sobre masculinidade (também) em corpos de mulheres. Outrossim, em outros periódicos, ressalto dois dossiês 9 recentes sobre lesbianidade e um dossiê ${ }^{10}$ dedicado a masculinidades, que, entre trinta e sete artigos, possuem apenas um texto aderente ao tema, ao estudar o caso de Luana Barbosa, lésbica masculinizada e assassinada em abordagem policial violenta e lesbofóbica (JESUS \& TORRES, 2017). A partir desses dados, é possível inferir que, em certa medida, uma parte da experiência lésbicosapatão ${ }^{11}$ tem sido invisibilizada na produção acadêmica voltada para publicação. Tal fenômeno pode se efetivar tanto por falta de espaço/interesse em/de tais periódicos, quanto por falta de interesse por parte da própria autoria acadêmica sobre o assunto. No entanto, importante ressaltar que, a partir dos exemplos, a invisibilização perpassa, também, o próprio efeito performativo do gênero, em que masculinidade emerge, no limite, como sinônimo de gênero masculino.

Assumindo, portanto, a importância do tema da masculinidade em mulheres, o presente artigo busca iniciar a aproximação entre anômalo e masculinidade por meio da relação que Deleuze e Guattari (1997) estabelecem entre anômalo e devir-animal, quando afirmam que este seria o devir que mais se avizinha daquele. Paola Gomes (2002), ao discutir esse devir, localiza na educação escolar e científica (evolucionista e positivista) apropriação paradoxal, que concebe os animais ao mesmo tempo como lócus de um princípio humano e como a falta de humanidade. Na religião católicoapostólica, por sua vez, há o demônio, do qual nos aproximamos quando de alguma

\footnotetext{
${ }^{7}$ Pesquisa realizada no dia 10 de julho de 2020, por meio da ferramenta de busca oferecida pelo próprio portal do periódico, unicamente com a palavra-chave masculinidade, nas revistas: Estudos Feministas (UFSC), Pagu (UNICAMP). A partir dos resultados, foram verificados os títulos, e aqueles que faziam menção ou relação direta entre masculinidade e homens foram contabilizados como artigos que concebem a masculinidade exclusivamente por meio dos homens. Quando esta relação direta não era encontrada no título, os resumos foram lidos. Ainda que alguns artigos possam ter assinalado no corpo do texto que a masculinidade não é monopólio dos homens, os que não trataram esta premissa enquanto tema ou foco analítico foram desconsiderados.

8 Na Revista de Estudos Feministas a pesquisa apontou 26 referências, nenhuma delas sobre masculinidade em mulheres. Na Revista Pagu, a busca sinalizou 27 artigos, dentre estes apenas o de Farias, Cecchetto e Silva (2014) com enfoque também, mas não exclusivamente, sobre mulheres.

9 Da revista Periódicus intitulado Sapatão é revolução! Existências e resistências das lesbianidades nas encruzilhadas subalternas, de 2017, e Dossiê Sáfico, de 2018, do periódico Criação e Crítica.

10 Da revista Periódicus, intitulado Masculinidades Contemporâneas em Disputa, de 2020.

${ }^{11}$ Não entendo masculinidade em corpos de mulheres como uma possibilidade exclusiva da experiência lésbica. Entretanto, como sinaliza Halberstam (1998), quando a masculinidade em um corpo interpelado pelo feminino emerge em uma existência não heterossexual, é capaz de produzir outros sentidos e, via de regra, não encontra escapatória de uma reprovação social.
} 
forma abdicamos de um aspecto de nossa humanidade - que, no caso, converge para uma concepção de humanidade retida pela moral cristã. "Controlar os instintos" e evitar "os furores biológicos” (Ibidem, p. 60) são condições necessárias para apartarse da potencialidade animal da humanidade, adverte a autora. Consequentemente, são, também, condições a serem replicadas - isto é, emuladas e, ambivalentemente, estranhadas - para devir-animal.

É neste sentido que devir-animal demanda uma condição anômala. Ao abdicar da humanidade, relacionar-se com ela, talvez, de um modo mais profundo. Refratária, estar, mais do que nunca, por ela interpelada. O humano, aqui, é biológico, mas é muito mais. É, a partir do que se é, dos órgãos que se tem, da fala que se pronuncia, dominar a si mesmo, dobrar-se sobre si, docilizar-se e, assim, conceber o humano "material". Devir-animal é animalizar-se enquanto indelével humano. Assim, a relação entre anômalo e devir-animal se efetiva por meio de um movimento paradoxal: o distanciamento e a aproximação do humano.

O anômalo, portanto, é aquela (ou aquilo) que está em vias de afastar-se do humano, sem, no entanto, dele se desfazer. Diz de uma aspereza, de uma desigualdade, de uma "ponta de desterritorialização12" (DELEUZE \& GUATTARI, 1997). Enquanto ser humano, tornar-se anômalo é colocar-se de modo ambivalente: entre humano e animal, entre anômalo e sujeito. Assim, o anômalo é aquilo ou aquela/e que se desterritorializa: vara fronteiras, desaprende, recomeça, estranha e torna-se estranha/o em seu próprio lar.

Isto posto, do modo como concebo o devir-sapatão, é sobretudo por relacionarse com a desterritorialização do humano que o anômalo pode ser deslocado de uma relação única com o devir-animal (mas partir dela contaminado) para produzir uma possibilidade de devir-sapatão. O anômalo, portanto, emerge como elemento, mas também como resultado em uma associação. Relaciona-se com os devires, afetando a condição do ser humano, e a partir disso contamina-se, produzindo a si mesmo, isto é, fazendo emergir a figura do anômalo. Constituindo, assim, condição para uma das formas de devir-sapatão.

\footnotetext{
12 Desterritorialização para Deleuze e Guattari está associada à ideia de território, de fronteiras e limites transponíveis em função de uma desterritorialização. É um olhar geográfico que se soma ao olhar histórico para produzir uma descontinuidade, um entrelugar. É, também, conceito determinante para a compreensão do devir-sapatão.
} 
Entretanto, ainda que o anômalo goze de certa antropomorfia, ele a excede, e é neste aspecto, também, que o anômalo supera os sentidos do senso comum, da abjeção e da anormalidade. Anômalo é, sobretudo, relação. Como interpreta a estudiosa de cinema e filosofia Fabiana Marcello (2009, p. 612), ao discutir a função do anômalo de Deleuze e Guattari, a relação com a/o outra/o, consigo mesma/o, com alguma coisa é condição imprescindível ao anômalo. Essa relação, por sua vez, é subjugada a um momento, a um instante da ordem do singular, porque marcada por um encontro cujos efeitos podem ser singularizados. A partir destes elementos que, entendo, estar em face do anômalo é possível. É preciso, no entanto, compor uma aliança com o que insurge, captura e provoca-nos a habitar, ainda que brevemente, um entre-lugar. Perder-se e, ao mesmo tempo, localizar-se, em função da emergência de um entre-lugar.

É neste sentido que não há relações familiares - ao menos não em um primeiro momento - com o anômalo, anunciam Deleuze e Guattari (1997), mas sim pactos, alianças. O familiar, neste marco teórico, supõe uma relação de conforto, de reconhecimento de si na/o outra/o. Diferentemente, por meio do anômalo há um convite: o de desafiliar-se e, então, voltar ao familiar enquanto herege, desertor. Pactuar com o diabo, para além de um esoterismo, configura a aproximação, ou melhor, a filiação à resistência: resistir é aproximar-se do anômalo, permanecer refratário é permanecer anômalo. Neste artigo, o anômalo toma a forma humana, mas o humano é apenas seu referente provisório, pois que o anômalo se faz insurgência por meio das relações que possibilitam o afastamento do humano-sujeito. Afastar-se do humano aqui pressupõe distanciar-se do feminino e da heterossexualidade, afastar-se de uma inteligibilidade, que não pode ser produto ou efeito apenas de um indivíduo, mas de um/a sujeito/a em relação com o seu entorno.

No entanto, justamente pelo afastamento do feminino, aqui mais uma peculiaridade: a masculinidade em mulheres. Um dos motivos pelos quais a masculinidade na mulher se faz impossibilidade, como já dito, reside na compreensão de que aquela é monopólio dos homens (HALBERSTAM, 1998). Justamente por isso, a masculinidade carrega consigo uma herança que excede a adjetivação de um tipo de vestimenta, gestos corporais ou mesmo de um corpo específico. Masculinidade engendra muito do que significa ser homem em uma sociedade marcada por iniquidades de gênero, raça e sexualidades.

Contudo, como observa Jack Halberstam (1998), a condição arbitrária da masculinidade revela-se, via de regra, apenas quando edifica outros corpos que não o 
do homem cisgênero, branco e de classe média. Consequentemente, usurpador tornase o "corpo estranho" em que habita - apropriado de um poder e de uma constituição, no limite, intangível. Tal condição, contraditoriamente, possibilita que esse corpo, ao forjar masculinidade, fragmente-a. De uma expressão naturalizada pelo/no/que concebe o homem, masculinidade passa a ser traduzida em aspectos, traços e atitudes que não necessariamente formam um todo masculino, e que podem ser localizados e mapeados porque emergem como apócrifos. Condição nítida em corpos socialmente constituídos mulheres, mas que se masculinizam, compondo um todo ambíguo ou mesmo masculino. A fragmentação da masculinidade possibilita, consequentemente, uma forma importante de resistência, uma vez que evoca também a decomposição da própria feminilidade. Um corpo ambíguo carrega em si traços de ambos, embaraçando o vínculo da masculinidade com uma essência própria do homem e sobretudo com uma existência vil - essência naturalizada no nível do discurso, mas que, na prática, faz-se vazia e, ao mesmo tempo, transbordante, para fazer referência à importante contribuição de Joan Scott (1995) sobre as categorias de gênero.

Como efeito, emerge a importância de demarcar a masculinidade das personagens aqui discutidas. Um ato político - e performativo - porque reivindica a masculinidade como um território habitável por quaisquer corpos (HALBERSTAM, 1998). Consequentemente, investe na inteligibilidade de outros tipos de masculinidade, ao ensejar que tais expressões excedam os sentidos fetichistas, exóticos e abjetos, tornando-se passíveis de contemplação e admiração.

É aqui, portanto, que se faz imperativo retornar ao anômalo para aproximá-lo da masculinidade. A relação da masculinidade na mulher com uma espécie de abjeção é o que permite esta aproximação, em um primeiro momento. Assim como no anômalo, a abjeção implica um distanciamento do que pode ser concebido como humano. Masculinizar-se enquanto corpo concebido socialmente como mulher possibilita uma espécie de desterritorialização que dificulta a inteligibilidade e, consequentemente, coloca em jogo a relação com o que é concebível como humano. No entanto, e de forma complementar, ainda que o anômalo aqui seja localizado em corpos de mulheres brancas que semasculinizam, ele não se reduz ao abjeto. $\mathrm{O}$ abjeto, caracterizado por Julia Kristeva (1982) e retomado por Butler (2013), constitui-se naquilo que está em excesso nos corpos, que deve ser expelido, descartado, escondido. É, portanto, aquilo que não queremos ver em nós mesmas/os, mas que, em alguma medida nos constitui. Butler (Ibidem) recorre a este conceito para discutir a banalização das violências que 
sofrem indivíduos cujos corpos não encontram referente na matriz heterossexual (e cisgênero, acrescento). Como efeito, o abjeto, ainda que componha uma possibilidade de anômalo, resume-se apenas ao rechaço, à ininteligibilidade violenta, enquanto o anômalo convoca a uma re(l)ação que pode ser transformadora e criativa, não apenas destrutiva. Duas são, portanto, as condições que afastam o anômalo de uma compreensão abjeta ou do senso comum: seu caráter singular (submisso que é aos acontecimentos), e sua potência criativa. A distância entre anômalo e abjeto ganha respaldo nas análises das cenas selecionadas. Porém, antes de discuti-las, apresento brevemente as personagens e as categorias de análise que compõem.

\section{Personagens e modos de olhar para o anômalo}

Tipping The Velvet é uma minissérie dramática, baseada no romance neovitoriano homônimo de Sarah Waters, publicado pela primeira vez em 1998. Foi exibida em três episódios pela BBC Two e produzida pela produtora independente Sally Head Productions. Dirigida por Geoffrey Sax e escrita por Andrew Davies ${ }^{13}$, a história é ambientada na Inglaterra, nos anos 1890, e narrada pela protagonista Nancy Astley, que conta a sua própria história. Nan, jovem mulher branca e até então heterossexual, narra como se apaixonou por um Drag King performer ${ }^{14}$, e por conta desta relação (e sua superação) mudou sua vida substancialmente. Nan, além de se reconhecer como lésbica, desafia lógicas de gênero ao apaixonar-se concomitantemente pela performance Drag King. Tais aspectos de sua vida oferecem uma instigante possibilidade de análise, na medida em que movimentam questões não apenas de sexualidade, mas também de gênero, sempre em relação.

Os olhares, as repreensões que Nan sofre e sua postura refratária mostram-se produtivos para pensar nas relações de gênero e sexualidade da forma como venho propondo neste artigo. Para Nan, encontrar-se em face do anômalo é experienciar algo que é da ordem do "primeiro", é estabelecer uma conexão em face do diferente, do, para ela, até então, inexistente.

\footnotetext{
13 Também conhecido por seu trabalho em House Of Cards.

14 Geralmente personificado por uma mulher (cis ou trans) ou pessoa transgênero, consiste na masculinização do corpo e na criação de um personagem. No caso da série, remete a mulheres que possuíam números artísticos em teatros, algumas reconhecidamente lésbicas. Hoje, tornou-se uma tradição da cultura queer e lésbica.
} 
Desse modo, as cenas aqui discutidas, selecionadas a partir de uma primeira análise dos três episódios da série, compõem a construção do anômalo a partir das personagens Nan e Kitty, e o que pode emergir de produtivo da relação que tal construção pressupõe. Foram escolhidas, portanto, cenas que fizeram emergir, a partir de uma ideia de sequencialidade - isto é, entendendo o anômalo como um processo contínuo e inacabado - o anômalo a partir de relações, instantes, singularidades que permitiram elaborações teórico-analíticas. As ferramentas teórico-metodológicas que auxiliaram a investigação contemplam a etnografia de tela (RIAL, 2004) adaptada para aspectos da linguagem seriada, de modo a compreender a tela como uma "teia de discursos" (BALESTRIN \& SOARES, 2012), como uma forma de se conceber a realidade. Há, portanto, dois elementos a se considerar no trabalho com essa metodologia. O primeiro diz respeito à concepção de discurso, que aqui deriva da teoria discursiva foucaultiana (FOUCAULT, 2000). Nesse sentido, o trabalho empreendido sobre o audiovisual compõe exercício descritivo-analítico, na medida em que descrever produz, em si, sentidos importantes, para além de apenas reproduzir - aqui, portanto, o potencial produtivo da linguagem é acionado, em consonância, também, com a teoria performativa de Butler (2013). O segundo refere-se ao que Julia Kristeva (1974) nomeia "intertextualidade" operando em qualquer audiovisual, que compreende a potencialidade de evocar e estabelecer relações entre diferentes "textos" sociais, sejam eles midiáticos ou não, e que evocam uns aos outros concomitantemente. Tal elemento é explorado na etnografia de tela na medida em que são operações discursivas que estão em voga ali. É nesse sentido que a busca por uma situação “da vida real” 15 - entendendo aqui o real como contrário de ficção -, não pode ser um pressuposto da etnografia quando operada em uma tela, uma vez que mesmo uma produção fictícia midiática faz circular discursos que atravessam os meios e a existência social mais amplamente, produzindo outras possibilidades dentro da própria realidade.

Um ponto importante do trabalho com a etnografia de tela reside sobre a compreensão de que os sentidos não estão prontos, obscurecidos à espera da pesquisadora que incidirá sobre eles a luz da ciência. Como explicam Balestrin e Soares (2012), tal operação etnográfica compreende os discursos como múltiplos e, ao mesmo

\footnotetext{
15 Não pressuponho que na etnografia tradicional a questão do realismo ou da veracidade seja questão já resolvida. No entanto, há uma diferença substancial entre um filme etnográfico, por exemplo, e uma série que se admite como ficção. É nesse sentido, sobretudo, que advogo por uma outra compreensão de realismo.
} 
tempo, singulares. Múltiplos uma vez que é em relação que os sentidos são construídos. Ou seja, há um elemento contingencial a operar na medida em que a etnografia é realizada, que compreende a relação entre pesquisadora e audiovisual, e o que pode ser construído a partir de um espaço e tempo específicos. Consequentemente, o produto desta relação, além de múltiplo, torna-se singular, na medida em que diferentes pesquisadoras podem (e certamente irão) produzir sentidos distintos na relação com um mesmo audiovisual. Assim, as cenas aqui selecionadas foram efeito de uma escolha analítica baseada em percepções teórico-orientadas, mas que também se fizeram imbuídas em percepções e concepções de ordem subjetiva. Por outro lado, esta perspectiva não rejeita o efeito reducionista das relações sociais e também da língua, o que impossibilita que qualquer sentido aleatório seja extraído de uma imagem. Com efeito, Balestrin e Soares (Ibidem) visualizam como uma das estratégias da etnografia de tela o olhar que duvida e estranha (d)os sentidos sociais mais, talvez, imediatos, o que torna tarefa desta metodologia priorizar um olhar que lance questionamentos sobre o status quo, de modo a evidenciar a coexistência de sentidos.

Entretanto, as ferramentas etnográficas não são suficientes para dar conta das especificidades das mídias. Por isso, a compreensão sobre a linguagem do audiovisual torna-se necessária. Rial (2004), Balestrin e Soares (2012) tomam emprestadas ferramentas metodológicas do cinema, atentando para planos, movimentos de câmera, críticas publicadas, montagem, som, etc. No caso deste artigo, tais ferramentas também são relevantes, mas meu olhar esteve voltado para como as séries fazem uso desses aspectos, de modo a compor uma experiência analítica mais complexa a respeito das cenas selecionadas. Tal experiência é relatada na sequência.

\section{Do anômalo que convoca a uma (r)existência: Nan}

Tipping the Velvet é uma minissérie que, desde sua estreia internacional, vem sendo motivo de amor e ódio entre estudiosas e críticas, ainda que no Brasil pouco interesse tenha despertado. A grande questão que tem movimentado trabalhos sobre a série parte do pressuposto de que o romance de Sarah Waters, em que a história se inspira, foi, de fato, revolucionário em termos de representatividade lésbica, para então perguntar se a série pode ser considerada o mesmo. Para alguns destes estudos, como o de Heather Emmens (2009), o universo serial foi elaborado especialmente para deleite do olhar masculino. Para dar suporte a seu argumento, a autora denuncia a falta 
de passabilidade lésbica da personagem principal ou, no momento em que esta traveste-se de homem, sua falta de passabilidade cisgênero. Além disso, destaca que o próprio roteirista de $T T V$, Andrew Davies, assume em uma coletiva de imprensa que os homens adorariam a série.

Figura 1 - Geoffrey Sax, Tipping The Velvet, DVD

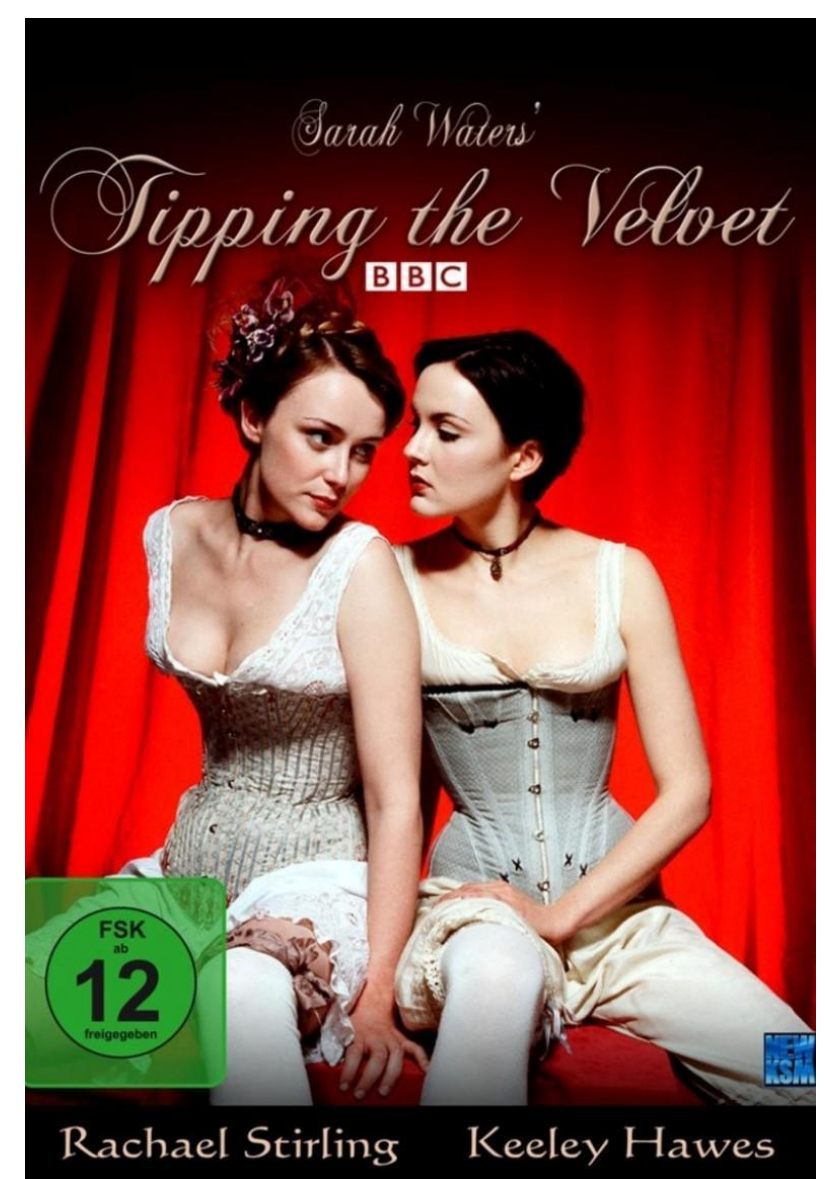

Fonte: Google (2021).

De fato, alguns aspectos do universo serial de $T T V$ permitem esta compreensão. Considerando-se a importância que a metodologia adotada encontra no potencial intertextual dos produtos midiáticos, para além de estudos sobre a série, evoco aqui a capa do DVD (Fig.1), uma vez que esta pode ser considerada apelativa nesse sentido. Nan e Kitty, sentadas lado a lado, vestindo apenas um corselet com um saiote provavelmente um vestuário íntimo - de forma alguma apresentam-se masculinizadas. Os olhares lascivos que trocam somam-se às roupas íntimas e evocam um feminino normativo e também apelativo.

Lea Madsen (2010), no entanto, pergunta-se se TTV pode ser simplesmente resumida a uma série voltada para o olhar masculino. Destaca a produção visual das cenas de sexo entre mulheres, uma produção, segundo a autora, verossímil e não 
fetichizada, e ressalta o contraste que tais cenas estabelecem com o momento em que Nan, travestido, prostitui-se para homens, incorporando um jovem rapaz, de modo a defender o compromisso ético da série com a produção de uma lesbianidade não estereotipada ou fetichizada.

É notório que ambas as autoras, ainda que ofereçam distintas possibilidades de leitura da série, preocupam-se sobretudo em identificar os sentidos oferecidos pela produção. Assim como Emmens (2009) recorre à fala citada do roteirista, Madsen (2010) especula, em diversos parágrafos de seu texto, o que pensa ser a intenção, seja da produção, seja do roteirista, ou do diretor, ao filmar tal adaptação para a TV. Ainda que os aspectos frisados pelas autoras e os sentidos que deles emergem sejam relevantes para este artigo, não priorizo, aqui, pensar sobre as "reais intenções" de quem trabalhou na criação e composição de $T T V$. Interessa-me, sim, a partir também das leituras das autoras, indagar: há espaço para a insurgência do anômalo e, a partir dele, para a produção de um devir-sapatão, no encontro entre Nan e Kitty e sua consequente produção de lugares de gênero e sexualidade, considerando que são duas personagens mulheres, brancas e, talvez, demasiadamente femininas?

Antes de abordar uma cena específica, contudo, gostaria de discorrer rapidamente sobre Nan e Kitty. Duas personagens que, repito, são classificadas pelas autoras consultadas como pouco masculinas e pouco lésbicas. Interessa-me partir desta compreensão que, do modo como entendo, pode ser apressada, e cotejá-la com expectativas imbuídas de/no gênero como poder, nos termos butlerianos. À luz desse referencial teórico, avaliar o potencial para masculinidade ou lesbianidade de Nan e Kitty é colocá-las em face daquilo que se espera de uma expressão masculina de gênero e lésbica de sexualidade. Nenhum mal aí, mas quando estas expectativas tornam-se razão para legitimar corpos, é inevitável operar com a mesma forma de normatização que o próprio gênero como poder opera. Nesse sentido, defendo que a medição do "grau" de masculinidade e de lesbianidade das personagens, ou a verificação de sua passabilidade, são objetivos contraproducentes para este artigo. Mais do que isso, acabam por legitimar aquilo que, justamente, busca-se desconstruir aqui, qual seja, o efeito normativo do gênero e da sexualidade. Como efeito, assumo como pressuposto que há masculinidade e há desejo entre mulheres em TTV, porque há vestígios: vestimentas, gestos, postura, desejo, amor. Parto desses aspectos, e a partir deles convido a leitora a acompanhar o exercício analítico de algumas cenas em que tais elementos estão operantes. 
Para Nan, proponho que o momento de encontro com o anômalo pode ser localizado aos 4 minutos do primeiro episódio, quando esta assiste, pela primeira vez, ao espetáculo protagonizado por Kitty Butler. Kitty sobe ao palco, com vestimentas masculinas, elegante e charmoso, mas ao mesmo tempo sem esconder que, apesar de compor um personagem do gênero masculino, é uma mulher. Canta músicas sobre ser um jovem homem, diverte uma plateia satisfeita e animada, exceto por uma pessoa, que destoa consideravelmente do resto da multidão: Nan. A jovem parece estar em transe. A cada movimento de Kitty, cada olhar, cada gesto, emerge uma Nan enfeitiçada, que mal pestaneja, talvez por medo de perder qualquer segundo do espetáculo. "Se dirá que o devir-animal é assunto de feitiçaria", nos dizem Deleuze e Guattari (1997, p. 29). Pois há feitiço também no devir-sapatão, porque opera um elemento da sedução, da captura, que parece colocar Nan em um transe.

Sem dúvida, desejo, paixão e admiração perpassam esse primeiro contato. Há uma aproximação do amor romântico, na medida em que Nan apaixona-se instantaneamente por Kitty. Entretanto, não é este aspecto que faz Kitty emergir como anômalo para Nan. Há outro elemento que atua enquanto Nan se vê "enfeitiçada", um elemento da ordem do primeiro: primeiro contato, primeira relação, primeira vez que uma existência - resistente - torna-se possibilidade. Kitty se faz anômalo diante de Nan porque oferece uma materialidade insurgente, algo da ordem, talvez, do impensado, do irreal - para a jovem Nan, ao menos. Assim, não é apenas o nascimento de uma paixão que se constitui diante de quem especta. É a primeira aliança, a primeira vez que o anômalo a capturou, que com Nan fez um pacto, um pacto de amar, de desejar, mas também de devir. 
Figura 2 - Still de Kitty. Geoffrey Sax, TTV (ep.1), 2002

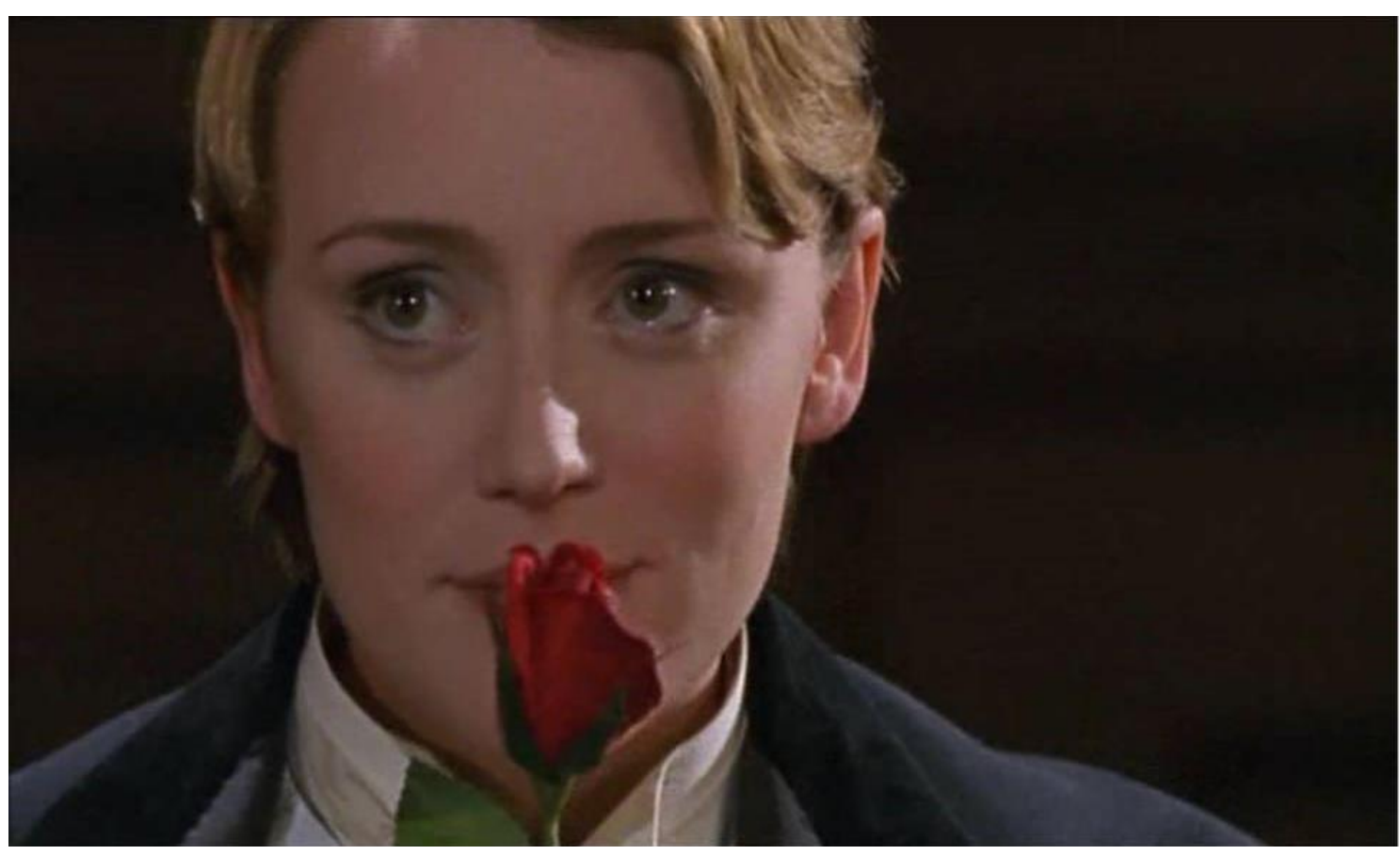

Fonte: Google (2021).

Há, ainda, um outro elemento que torna esta captura maior que o nascimento de uma paixão: o visível desconforto de Nan ao deparar-se com alguém como Kitty. Ao final de sua performance, Kitty (Fig.2), em um gesto galanteador, porta uma rosa enquanto caminha pelo palco, procurando uma dama a quem entregá-la. Seus olhos cruzam com os de Nan, o momento é de tensão. Kitty exclama: "pega”, e arremessa a rosa na direção da jovem. O rugir de tambores, que acompanhava a cena quase que de forma inaudível até então, avoluma-se, enquanto a flor rodopia no ar, em direção a uma Nan perplexa, paralisada, e, agora, sozinha na plateia. Tudo à sua volta deixa de existir, apenas a flor é o que importa. No entanto, com o tilintar dos pratos da bateria, a rosa chega ao seu destino, nas mãos de outra mulher, que se encontra atrás de Nan. A jovem parece, neste instante, despertar de seu transe, e seu semblante se desvanece, visivelmente triste com o desfecho do evento. Enquanto Kitty se despede da audiência e uma nova atração é chamada ao palco, Nan põe a mão no coração, em um visível mal estar, pede licença e se retira. Seu desconforto emocional parece se traduzir também em desconforto físico. Esteve em transe, mas em luta: o encontro com Kitty pareceu fasciná-la e perturbá-la. Desorientada, deixa a rosa passar, e com ela a possibilidade de uma aliança. Retira-se, já não pode estar ali. Pois é justamente enquanto elemento desestabilizador que Kitty se faz anômalo frente à Nan. O efeito da captura emerge da 
junção entre um território comum, confortável, conhecido (plateia), e a insurgência de um outro que pouco ou nada se assemelha ao banal (palco), e que convida a uma desterritorialização de si. Nan não buscava desterritorializar-se naquela noite, não buscava conhecer ou experimentar algo diferente daquilo que lhe era familiar. Justamente por isso o encontro com Kitty torna-se mais devastador: insurge, diante dela, uma existência outra que provoca desejo e medo, uma existência desterritorializada, múltipla - mulher masculina, homem de mentira. Uma existênciaanômalo.

Após esse primeiro encontro, Nan permanece com a lembrança da performance de Kitty vívida e inquieta em sua mente. Aos 10'09" do primeiro episódio, está na fábrica de seu pai, lugar em que trabalha, limpando ostras ao lado da irmã, e as duas conversam. Nan fala de Kitty com entusiasmo, causando estranhamento na irmã, que a escuta. Comenta, em certo momento, que jamais havia conhecido uma garota como Kitty, e que sequer sabia que existiam garotas assim. De repente, visivelmente incomodada, sua irmã exclama: "Elas não são pessoas como nós”. Nesse momento da narrativa, a fala da irmã soma-se a de outros dois homens que já haviam advertido à protagonista: "Kitty não é um garoto de verdade".

Considerando o efeito intertextual e a escolha por uma metodologia que não trabalha com a polarização real/ficção, evoco aqui as considerações de Gillian Rodger (2018, p. 23), que, ao pesquisar Drag Kings ${ }^{16}$ nos chamados varieties shows - como o que Kitty compõe em Tipping The Velvet - destaca excerto de um crítico de teatro do século XIX, que parece estupefato e, ao mesmo tempo, fascinado com estes performers:

Embora eles/as não sejam como os homens, [elas/es] são na maioria dos seus atributos diferentes das mulheres, parecendo criaturas de um sexo alienígena, parodiando ambos os gêneros. Foi certamente chocante vislumbrá-las/os com sua horrível beleza, seu jeito zombador e sem encanto, sua vergonhosa graça (tradução minha). ${ }^{17}$

O crítico em questão parece compartilhar da ambiguidade que permeia a fala de todas as personagens a respeito de Kitty, tentando traduzir em palavras o efeito avassalador que tal expressão de gênero pode causar. Recorre a relações paradoxais:

\footnotetext{
${ }^{16}$ No original a autora define a prática como de cross-dressing. No entanto, pelos significados identitários e de expressão política que constituem a palavra travesti, optei por fazer uso da nomenclatura Drag King, por seu caráter também de provisoriedade e sua conexão com a vida artística. 17 No original: "Though they are not like men, [they] were in most things as unlike women, and seemed creatures of a kind of alien sex, parodying both. It was certainly socking to look at them with their horrible prettiness, their archness in which was no charm, their grace which put to shame."
} 
"horrível beleza", ou a palavras, senão paradoxais, que expressam um sentido muito próximo disso. O crítico, por meio de oxímoros, mais do que produzir frases dúbias, expõe o caráter de multiplicidade da expressão Drag King. Multiplicidade, neste caso, não quer dizer múltiplo. Como evidenciam Deleuze e Guattari (1997), multiplicidade relaciona-se sobretudo com coexistência do que com alternativas de escolha. Assim, beleza e feiura tornam-se capazes de coabitar em um corpo que se traveste, justamente porque nele se engendram práticas ambivalentes de gênero. As incompletudes às quais recorre também expõem o efeito da multiplicidade: nem como homens, nem como mulheres. A resolução dicotômica já não é suficiente. Ineficaz em sua tentativa de encontrar um gênero que sirva de abrigo a tais performers, resolve a questão sentenciando-as a uma terceira possibilidade que relação alguma parece ter com o gênero: paródias, alienígenas. Curiosamente, são leituras produzidas sobre uma performance artística que tem como tema o gênero, mas que dizem daquilo que lhes falta, reduzindo-as a mero simulacro. O efeito do gênero como prática torna-se explícito, assim como sua capacidade de produzir algo que não pode ser confundido, aqui, com o gênero como poder (BUTLER, 2013), ainda que dele derive.

Assim como no excerto crítico, para aquele coletivo de TTV (Nan, irmã e homens que advertiram Nan) pessoas como Kitty são mais definidas pelo que lhes falta do que pelo que são. Isso acontece porque o referente que emerge para a existência de Kitty se faz nos extremos de uma binaridade: mulher-feminina/homem-masculino. Kitty, enquanto mulher masculina, não é nem garota ("ela não é como nós", diz a irmã de Nan) e nem garoto ("de verdade", dizem os homens que convivem com Nan). Em contrapartida, tal compreensão também possibilita outro olhar, aquele que observa as presenças. Se é necessário evocar que Drag Kings como Kitty não são como homens, não seria porque, em certo sentido, o são? Consequentemente, se é preciso diferenciálos das mulheres, não seria porque também delas se aproximam? Como efeito, parodiar os gêneros é admitir que ali coexistem expressões de gênero que, em teoria, não podem habitar o mesmo corpo, e o efeito disso é uma série de paradoxos - inclusive da ordem das sensações. Em outras palavras, a ambiguidade de gênero traduzida nos corpos destas performers provoca uma ambiguidade (no limite paradoxal) de sensações e reações na audiência. A performatividade implicada em tal paródia denuncia sua farsa (BUTLER, 2013), possibilitando leituras que categorizam as atrizes e suas 
performances como "não passáveis", seja em termos de gênero ou de sexualidade ${ }^{18}$. No entanto, considerando a multiplicidade de sentidos que emergem dos discursos ali acionados, a paródia torna, ao mesmo tempo, exposta a possibilidade de emular os gêneros, e, mais do que isso, de expressões de gêneros, ambas convocadas, coexistirem: mulher (masculina), garoto (de mentira).

Há então duas questões primordiais que emergem como efeito da incapacidade da língua de engendrar corpos que se travestem. Como explica Halberstam (1998), o que torna as categorias mulher e homem tão efetivas é justamente o fato de não haver a possibilidade de uma produção perfeita. Se gênero é também um processo, uma prática (BUTLER, 2013), mesmo o homem mais masculino ou a mulher mais feminina poderá experimentar certo desvio da norma. Mais do que referentes, tais categorias forjam uma busca, enquanto destino que um corpo nomeado mulher ou homem precisa constantemente assumir para manter o mínimo de inteligibilidade (porém, via de regra, ninguém se contenta com o mínimo, pois a inteligibilidade de gênero não é apenas uma necessidade). Como efeito, a segunda questão retorna à produção de multiplicidade pelas pessoas que sentenciam Kitty e mulheres como ela à falha (e falta) constante dentro de uma matriz de gênero. A potência reside nas frustrantes tentativas de gendrar Kitty e suas semelhantes e, sobretudo, na recusa por uma determinação de terceiro tipo, pois como afirma Halberstam (1998 p. 28), tal determinação apenas "equilibra o sistema binário e, ademais, tende a homogeneizar diferentes variações sob a bandeira da/o “outra/o"19 (tradução minha).

Entre mulher e não mulher, Kitty, portanto, habita um território abjeto para aquelas/es à volta de Nan. Porém, Nan recusa-se a compactuar com essa abjeção. Cria um outro lugar para Kitty. Ainda que sinta os efeitos das advertências feitas pelo seu entorno, isso não a impede de se fascinar pela performer. Diferentemente de todas/os a sua volta, Nan, neste primeiro encontro, experienciou outra possibilidade, formou o princípio de um pacto com Kitty, permitindo que essa se fizesse anômalo - e não, simplesmente, abjeta. E esse pacto não permanece platônico.

Nan de fato é capaz de atravessar a barreira discursiva imposta pelo seu entorno e aproxima-se de Kitty a ponto de tornar-se sua assistente. Aos 34" do primeiro episódio, Nan vê-se sozinha com as roupas masculinas da performer, e decide

\footnotetext{
${ }^{18}$ Efeito que, inclusive, reverbera em estudos sobre a série, como o de Emmens (2009).

${ }^{19}$ No original: "'thirdness' merely balances the binary system and, furthermore, tends to homogenize many different gender variations under the banner of "other".
} 
experimentá-las. Esconde o cabelo comprido no chapéu e começa a dançar e cantar em frente ao espelho, imitando sua amada. Então, olhando para o espelho, declara seu amor por Kitty enquanto beija sua imagem refletida. Kitty flagra a protagonista, que se constrange prontamente. No entanto, Kitty, fascinada pela figura da, até então, amiga, confessa que poderia muito bem se apaixonar "por um rapaz como ela”. Pede um beijo. Nan aproxima-se, e antes de beijá-lo, Kitty o elogia mais uma vez: "que lindo rapaz”. Beijam-se. Nas próximas cenas, Kitty e Nan ensaiam juntos, pois Nan torna-se o parceiro de Kitty nas apresentações. Cantam e dançam ao som de "Following My Father Footsteps", canção que casualmente conta a história de um menino que está aprendendo com o pai a ser "homem", nesse caso, a como portar-se e como conquistar mulheres. Na sequência, Nan encontra-se sentada em frente a outro espelho, enquanto um barbeiro se prepara para cortar seu cabelo. Ao ver-se com o cabelo curto, olha para Kitty e diz, perplexa e entusiasmada: “agora sou como você”.

Nan, que ao início deste artigo encontrava-se em face do anômalo, agora aproxima-se dele mais do que nunca. Sua imagem refletida é um testemunho de si, de seu pacto com Kitty, com uma outra família, com o anômalo. Beija seu reflexo ao declarar seu amor em frente ao espelho. Mas beijar-se talvez não tenha o simples sentido de simular sua amada a sua frente. Talvez beijar-se tenha a ver também com apropriar-se de vez deste território outro. Apropriar-se do "lindo rapaz", tomar a dama em seus braços e beijá-la. Nan passa a ser daquelas que "não são como nós", está a tornar-se outra/o. Aprendendo com a música como um homem "deve" se portar, constitui-se a partir de uma existência-processo, apropria-se, o quanto pode, de "seu" gênero, tendo em vista as amarras impostas pelo efeito performativo. Feita em multiplicidade, começa a transitar por um território que tomou como seu, assumindo o preço dessa união: jamais voltar ao território de partida como se partiu. Ao ser uma mulher "diferente das outras", está condenada a viver como nômade pelos lugares de gênero e de sexualidade. Ao cortar o cabelo, em um passado cujo cabelo curto era monopólio dos homens, a impossibilidade de voltar a ser como era torna-se irrevogável: "agora sou como você”.

Este é o ponto que atravessa a paixão e possibilita a emergência e o encontro com o anômalo: de espectadora à atração, de mulher "como as outras" à paródia dos gêneros, de uma paixão a uma forma de existência. É assim que, em face do anômalo, Nan é capturada por uma outra significação do seu gênero e da sua sexualidade, que permite conceber o modo de existência Drag King para além do abjeto, visão tão 
compartilhada por todas/os a sua volta. Nan, ao travestir-se, é beijada por Kitty pela primeira vez. Tal beijo é atravessado por diversos vetores de gênero e sexualidade: Nan personifica um Drag King, Kitty porta um vestido e maquiagem. Duas mulheres, no entanto, um beijo que toma forma a partir de lugares de gênero ambíguos, uma vez que Kitty decide apenas beijá-la quando Nan personifica um menino, ainda que as duas tenham estado muito próximas antes disso. Kitty assume poder se apaixonar por um garoto como Nan. Nan, garoto (de mentira), Nan, mulher (masculina). Este é o "garoto" anômalo que encantou à Nan, e que, agora, enfeitiça Kitty. A emergência, ou melhor, a insurgência avassaladora desse leque de possibilidades (de ser, estar e amar), a edificar o encontro com o anômalo, configura uma das formas de devir-sapatão.

\section{Considerações finais}

O presente artigo operou uma análise sobre a personagem Nan Astley, da minissérie Tipping The Velvet, de modo a dar forma a uma possibilidade de devirsapatão por meio da lesbianidade e da masculinidade em corpos de mulheres. $\mathrm{O}$ conceito de anômalo de Deleuze e Guattari (1997), assim como o de performatividade (BUTLER, 2013), foram os escolhidos para tecer esta emergência, possibilitando localizar os efeitos das expressões de gênero e sexualidade em relação com suas respectivas matrizes, assim como os gestos e interações submissos a acontecimentos e encontros, categorizados aqui como da ordem do singular.

Nan esteve em face do anômalo e, com ele, estabeleceu uma espécie de pacto. Nan, ao assistir pela primeira vez a uma performance Drag King e apaixonar-se por um Drag King performer, foi convidada a atravessar limites de gênero e de sexualidade que pouco imaginava que poderiam ser atravessados. A jovem, ao formar um pacto com o anômalo, pode compor outro tipo de relação com Kitty, em contraste com aqueles/as que a cercaram, além de se manter refratária às expectativas de gênero e sexualidade partilhadas, via de regra, por garotas como ela.

Apesar das questões específicas da masculinidade serem um dos pontos importantes para as análises, o anômalo não se resumiu à masculinidade, e nem mesmo a Kitty; antes, foi efeito de um acúmulo de forças da ordem do acontecimento, portanto, singulares. Cada gesto e fala resistentes às matrizes de feminilidade e heterossexualidade possibilitou a emergência do anômalo em Kitty, mas somente 
porque uma aliança foi forjada, porque nessas relações a resistência se fez, também, virtuosa existência.

E é por isso que os "excertos" de Nan e Kitty possibilitaram localizar o devirsapatão. Submetidas a acontecimentos da ordem do singular, produziram entre lugares: entre gêneros, entre sexualidades, entre famílias consanguíneas e pactos familiares, entre expectativas e materialidades inconformadas. Duas mulheres masculinas, dois garotos de mentira, dois modos de existência que produzem, no ato mesmo de ser, inteligibilidade. Em face do anômalo, devir-sapatão.

\section{Referências}

BALESTRIN, Patrícia Abel; SOARES, Rosângela. "Etnografia de tela": uma aposta metodológica. In: Metodologias de Pesquisas pós-críticas em educação. Dagmar Meyer e Marlucy Paraíso (Orgs.). Belo Horizonte: Mazza Edições, 2012.

BUTLER, Judith. Bodies that matter: on the discursive limits of "sex". New York: Roudedge, 1993

BUTLER, Judith. Changing the subject: Judith Butler's Politics of Radical Ressignification. Gary Olson and Lynn Worsham, JAC 20 (4), 2000.

BUTLER, Judith. Problemas de gênero. Feminismo e subversão da identidade. Rio de Janeiro: Civilização brasileira, 2013.

BUTLER, Judith. Regulações de Gênero. Cecília Holtemann (trad.). Cadernos Pagu, (42), janeiro-junho de 2014, p. 249-274.

CONEGATTI, Daniela. Devir-Sapatão: tensionamentos a partir de séries televisivas e de Video on Demand. 2020. Tese (Programa de Pós-Graduação em Educação) -

Universidade Federal do Rio Grande do Sul, Faculdade de Educação, Porto Alegre, RS, Brasil.

CRUZ, Cristiane Ferreira da Maia; ABREU, Eliane Fernandes. A origem de Thêmis. Abril, 2016. Disponível em: <https://jus.com.br/artigos/48436/a-origem-da-themis> Acesso em: 28 Ago. 2020.

DELEUZE, Gilles; GUATTARI, Felix. Mil platôs - capitalismo e esquizofrenia - vol. 4. Suely Rolnik (trad.) São Paulo: Ed. 34, 1997.

DERRIDA, Jacques. Margens da filosofia. Campinas: Papirus, 1991.

EMMENS, Heather. Taming the Velvet: Lesbian Identity in Cultural Adaptations of Tipping The Velvet. In: Adaptation in Contemporary Culture: Textual Infidelities. Racher Carroll (org.) Bloomsbury collections, 2009.

FOUCAULT, Michel. A arqueologia do saber. 6 ed. Rio de Janeiro, Forense Universitária, 2000. 
GOMES, Paola Basso Menna Barreto. Devir-Animal e Educação. Educação e Realidade, 27(2), jul./dez. 2002, p. 59-66. Disponível em: <https://www.seer.ufrgs.br/educacaoerealidade/article/view/25916/15185> Acesso em: 17 jul. 2020, p. 60.

HALBERSTAM, Jack. Female Masculinity. Duke University Press, 1998.

JESUS, Lilian Alves; TORRES, Igor. Uma análise interseccional da morte: Luana Barbosa e a insubordinação às estruturas. Periódicus. V. 1, n. 7, 2017.

KRISTEVA, Julia. Introdução à Semanálise. São Paulo: Perspectiva, 1974.

KRISTEVA, Julia. Powers of horror: an essay on abjection. New York: Columbia UP, 1982.

MADSEN, Lea Heiberg. Lesbian Desire And Mainstream Media: Sarah Waters' Tipping The Velvet on the screen. Odisea, n.11, 2010, p. 103-112.

MARCELLO, Fabiana de Amorim. Sobre crianças e encontros: singularidades em jogo na estética cinematográfica. Educ. Soc., Campinas, v. 30, n. 107, p. 611-630, Aug. 2009. Available from <http://www.scielo.br/scielo.php?script=sci_arttext\&pid=So101$73302009000200015 \& \operatorname{lng}=\mathrm{en} \& \mathrm{nrm}=\mathrm{iso}>$. Acesso em: 28 ago. 2020. https://doi.org/10.1590/So101-73302009000200015. P. 612.

RIAL, Carmen. Antropologia e Mídia: Breve Panorama das Teorias de Comunicação. In: Antropologia em primeira mão / Programa de Pós-Graduação em Antropologia Social, Universidade Federal de Santa Catarina, 2004.

RODGER, Gillian. Just one of the boys - female-to-male cross-dressing on the american variety stage. Universtity of Illinois, 2018.

SALIH, Sara. Judith Butler e a Teoria Queer. Guacira Louro (trad.). 1 ed. Belo Horizonte: Autêntica Editora, 2013.

SCOTT, Joan. Gênero: uma categoria útil de análise histórica. In: Educação e Realidade. 20(2), jul./dez. 1995, p. 71-99. 